\title{
Effects of arsenic on growth, saponins and flavoids yield of Panax notoginseng (Burk. F.H. Chen) and its control measurements
}

\author{
N. Li, S.C. Cheng, X.Y. Mei, Q. Li \& Y.Q. Zu \\ College of Resources and Environment, Yunnan Agricultural University, Kunming, P.R. China
}

\begin{abstract}
Arsenic stress inhibited the growth of Panax notogensing. The citric acid and phosphorus fertilizer can promote the growth of notogensing, increase the biomass and morphological index, improve the efficacy of saponins and flavonoid contents. They also make it release of soil arsenic, increasing arsenic content in Panax notogensing to exceed the standard, phosphorus is not conducive to the release of arsenic in soil, reducing the absorption of arsenic in plants.
\end{abstract}

\section{INTRODUCTION}

Arsenic (As) is a naturally toxic element and widely distributed in the environment, and it is cancerogenic to humans. Environmental As pollution in soil has become more and more severe problem (Dudka \& Adriano, 1997; Zhou et al., 2016). High soil arsenic background value, which was mean $65.6 \mathrm{mg} \mathrm{kg}^{-1}$ in the range of 6.9 to $242.0 \mathrm{mg} \mathrm{kg}^{-1}$, was found in Wenshan province. the main production area of Panax notoginseng (Burk. F.H. Chen), which has been cultivated for importantly traditional medicine in China, Panax notoginseng is an herbal species in the genus of Panax, family of Araliaceae (Dahui et al., 2014; Guo et al., 2010). The mining activities and unreasonable fertilization could cause arsenic content exceeding the standard and affect the growth and quality of $P$. notogensing.

\section{METHODS/EXPERIMENTAL}

Field experiments were carried out in Dalongtan village $\left(22^{\circ} 39^{\prime} \mathrm{N}, 103^{\circ} 06^{\prime} \mathrm{E}\right.$, elevation $\left.2251 \mathrm{~m}\right)$, Xundian County, Kunming prefecture, Yunnan province, China. Each plot was $3 \mathrm{~m}^{2}$ in size. Soil collected from the 0 $15 \mathrm{~cm}$ soil layer was mixed with the As stock solutions with $\mathrm{As}(\mathrm{V})$ 0, 20, 80, 140, 200, $260 \mathrm{mg} \mathrm{kg}^{-1}$ (prepared using $\mathrm{H}_{3} \mathrm{AsO}_{4}$ ). The As treated soil was incubated for two weeks. Soil before As treatment had a pH 5.32, organic matter content of $16.77 \mathrm{~g} \mathrm{~kg}^{-1}$, total $\mathrm{N}$ content of $0.60 \mathrm{~g} \mathrm{~kg}^{-1}$, total $P$ content of $1.20 \mathrm{~g} \mathrm{~kg}^{-1}$ and As content at $12.00 \mathrm{mg} \mathrm{kg}^{-1}$. Soil type was upland red soil with clay loam texture. Plot and pot experiments were conducted to study effects of citric acid $(0,4$, $6,8 \mathrm{mmol} \mathrm{kg}^{-1}$ ) and calcium magnesium phosphate fertilizer $\left(0,60,120,180 \mathrm{mg} \mathrm{kg}^{-1}\right)$ on growth, photosynthesis and medicinal components flavonoids and spanins of $P$. notogensing under arsenic stress.

\section{RESULTS AND DISCUSSION}

The results showed that: (1) The biomass and plant growth under As $140 \mathrm{mg} \mathrm{kg}^{-1}$ treatment significantly decreased compared with control $\left(0 \mathrm{mg} \mathrm{kg}^{-1}\right.$ As treatment). For biennial $P$. notoginseng, arsenic stress had no significant effect on the contents of saponins. For triennial P. notoginseng, there was a negative correlation between content of saponins and content of arsenic $(\mathrm{P}<0.05)$. There were no significant changes in PAL, SS and CHS enzyme activities of the $P$. notoginseng enzymes in the biosynthesis of flavonoids in triennial P. notoginseng. (2) Arsenic concentrations in main root under $140 \mathrm{mg} \mathrm{kg}^{-1}$ and $8 \mathrm{mmol} \mathrm{kg}^{-1}$ citric acid treatment reached the highest and increased by $30 \%$ coping with non citric acid treatment. Citric acid promoted the synthesis of photosynthetic pigments, increased the content of photosynthetic pigments, decreased the content of malondialdehyde (MDA). Citric acid effectively improved the flavonoids accumulation (Fig. 1). Under As $140 \mathrm{mg} \mathrm{kg}^{-1}$ treatment, flavonoid accumulation increased by $29 \%$ with $8 \mathrm{mmol} \mathrm{kg}^{-1}$ citric acid application. (3) The content of arsenic in $6 \mathrm{mmol} \mathrm{kg}^{-1}$

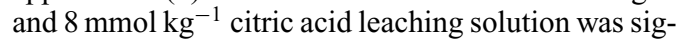
nificantly higher $21 \%$ and $33 \%$ than that of non citric acid leaching solution, respectively. Compared with non citric acid, contents of F2 (specifically adsorbed arsenic), F3 (weak crystalline iron and aluminum oxide hydrate combination fraction) and F4 (crystalline hydrated iron aluminum oxide with arsenic) of $8 \mathrm{mmol} \mathrm{kg} \mathrm{kg}^{-1}$ citric acid increased by $11 \%, 33 \%$ and 


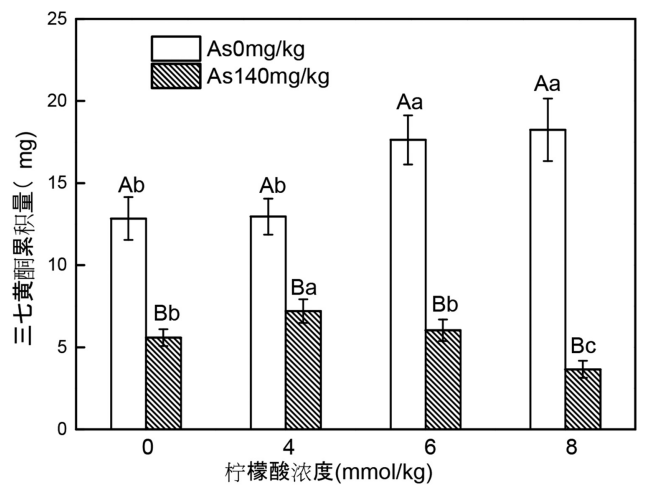

Figure 1. Effect of citric acid on the flavonoids accumulation under As $140 \mathrm{mg} \mathrm{kg}^{-1}$ treatment.

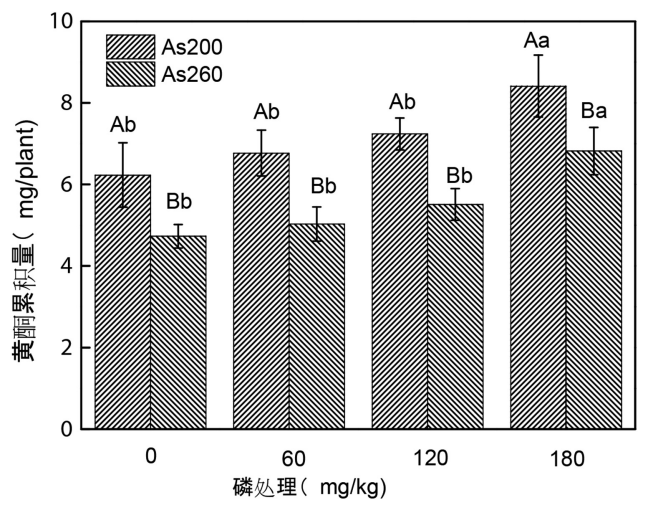

Figure 2. Effect of different $P$ levels on flavonoids accumulation of $P$. notoginseng under As stress.

$32 \%$, respectively. (4) Phosphate fertilizer could significantly improve the $P$. notogensing biomass under As concentration of $200 \mathrm{mg} \mathrm{kg}^{-1}$ and $260 \mathrm{mg} \mathrm{kg}^{-1}$ and phosphate fertilizer $180 \mathrm{mg} \mathrm{kg}^{-1}$ treatment, biomass significantly increased by $56 \%$ and $17 \%$. Plant heights were significantly increased by $5 \%$ and $26 \%$, respectively; the leaf area increased by $33 \%$ and $41 \%$.
Flavonoids accumulation increased under different P treatment levels (Fig. 2).

\section{CONCLUSIONS}

Arsenic stress inhibited the growth of Panax notogensing, the citric acid and phosphorus fertilizer can promote the growth of notogensing, increased the biomass and morphological index, improve the efficacy of saponins and flavonoid content, but also easy to make soil arsenic release, lead arsenic content exceed the standard, phosphorus is not conducive to the release of arsenic in soil thus, reduce the absorption of arsenic in plants.

\section{ACKNOWLEDGEMENTS}

The study was supported by the National Natural Science Foundation of China (Grant Nos. 41261096 and 31560163).

\section{REFERENCES}

Dahui, L., Na, X., Li, W., Xiuming, C., Lanping, G., Zhihui, Z., Jiajin, W. \& Ye, Y. 2014. Effects of different cleaning treatments on heavy metal removal of Panax notoginseng (Burk) FH Chen. Food Addit. Contam. Part A 31(12): 2004-2013.

Dudka, S. \& Adriano, D.C., 1997. Environmental impacts of metal ore mining and processing: a review. J. Environ. Qual. 26(3): 590-602.

Guo, H.B., Cui, X.M., An, N., \& Cai, G.P., 2010. Sanqi Ginseng (Panax notoginseng (Burkill) F.H. Chen) in China: distribution, cultivation and variations. Genet. Resour. Crop Ev. 57(3): 453-460.

Zhou, Q., Guo, J.J., He, C.T., Shen, C., Huang, Y.Y., Chen, J.X., Guo, J.H., Yuan, J.G. \& Yang, Z.Y. 2016. Comparative transcriptome analysis between low- and high - cadmium - accumulating genotypes of Pakchoi (Brassica chinensis L.) in response to cadmium stress. Environ. Sci. Technol. 50(12): 6485-6494. 